\title{
Long term follow up of patients with implantable cardioverter-defibrillators and mild, moderate, or severe impairment of left ventricular function
}

\author{
Hans-Joachim Trappe, Paul Wenzlaff, Petra Pfitzner, Hans-Gerd Fieguth
}

\begin{abstract}
Objective-To determine whether patients with life threatening ventricular tachyarrhythmias, impaired left ventricular function, and severe heart failure will benefit from implantable cardioverterdefibrillator (ICD) treatment.

Design-410 patients were followed up after ICD implant. Left ventricular function was assessed by the New York Heart Association (NYHA) functional class of heart failure: 50 patients $(12 \%)$ were in NYHA I-II, 151 (37\%) in NYHA II, 117 $(29 \%)$ in NYHA II-III, and $92(22 \%)$ in NYHA III. Epicardial ICD implantation was performed in 209 patients $(51 \%)$ and 201 patients (49\%) received non-thoracotomy ICDs.
\end{abstract}

Results-Perioperatively, 12 patients (3\%) died, more often after epicardial ICD implant (11/209 patients, 5\%) than after transvenous implant (1/201 patients, $<1 \%)(P<0.05)$. During a mean (SD) follow up of 28 (24) months (range $<1$ to 114 months), 90 patients (23\%) died: nine (2\%) died from sudden arrhythmia; five (1\%) also died suddenly but probably not from arrhythmic causes; 55 (14\%) died from cardiac causes (congestive heart failure, myocardial reinfarction); 21 (5\%) died from non-cardiac causes. The three year, five year, and seven year survival was $92-96 \%$ for arrhythmic mortality in NYHA class I, II, and III, compared to a three year survival of $94 \%$ and a five year and seven year survival of $84 \%$ for patients in NYHA class II-III. 338 patients (82\%) received ICD shocks (21 (SD 43) shocks per patient); patients in NYHA class II (83\%), class II-III (84\%), and class III (90\%) received ICD discharges more often than those in class I-II $(64 \%)(P<$ 0.05 ). The mean (SD) time interval between ICD implant and the first ICD shock was shorter in NYHA class II (16 (17) months), class II-III (19 (27) months), and class III (16 (19) months) than in class 0 -I $(22$ (24) months) $(P<$ 0.05).

Conclusions-Patients with mild, moderate, and severe left ventricular dysfunction benefit from ICD treatment and these patients survive for a considerable time after the first shock. Survival is influenced by the degree of left ventricular dysfunction; aggressive treatment of heart failure is necessary as well as ICD therapy.
(Heart 1997;78:243-249)

Keywords: cardioverter-defibrillator; heart failure; sudden death; ICD discharges

Sudden cardiac death is one of the major causes of mortality in western countries, with an incidence of 500000 sudden deaths per year in the United States and 400000 in Europe. ${ }^{12}$ It has been shown that the risk of sudden cardiac death increases with the severity of left ventricular dysfunction. ${ }^{3-5}$ Although treatment for congestive heart failure has improved markedly during the last 20 years, prognosis is still poor in patients with severe heart failure, with an annual mortality of $50 \% .^{6}$ Several studies have suggested that the implantable cardioverter-defibrillator (ICD) prevents sudden cardiac death in patients with life threatening ventricular tachyarrhythmias and impaired left ventricular function. ${ }^{7-9}$ However, the extent of the clinical benefit or long term survival is unclear and it is unknown to what extent patients with different degrees of heart failure will benefit from ICD implantation. The present study summarises our experience of ICD treatment in patients with mild, moderate, or severe heart failure during a period of more than 10 years.

\section{Methods}

PATIENTS

Four hundred and ten patients (368 male, 42 female), mean (SD) age 57 (11) years (range 10 to 78 years), were consecutively included in the study. Coronary artery disease was present in 279 patients $(68 \%)$, congestive cardiomyopathy in $76(19 \%)$, left or right ventricular dysplasia in $22(5 \%)$, and the remaining 33 $(8 \%)$ had another underlying disease (congenital heart disease, valvar heart disease, idiopathic ventricular tachycardia, or ventricular fibrillation). Symptomatic, drug refractory, sustained (duration $>30$ seconds) ventricular tachycardia or ventricular fibrillation was present in 403 patients (98\%); 15 patients $(2 \%)$ underwent prophylactic ICD implantation according to the MADIT or CAT study protocols. ${ }^{1011}$ Antiarrhythmic drug treatment had failed to suppress life threatening ventricular tachyarrhythmias in any of the patients, and they had received a mean of $3.3(2 \cdot 7)$ antiarrhythmic drug trials (range 1-14 drugs per patient) before ICD implantation.

The degree of heart failure was assessed according to the New York Heart Association 


\begin{tabular}{|c|c|c|c|c|}
\hline & \multicolumn{4}{|l|}{ NYHA class } \\
\hline & $I-I I$ & $I I$ & $I I-I I I$ & $I I I$ \\
\hline No of patients & 50 & 151 & 117 & 92 \\
\hline Mean (SD) age (years) & $48(15)$ & $49(10)$ & $57(10)$ & $59(11)$ \\
\hline Range & 10 to 71 & 15 to 78 & 23 to 78 & 31 to 77 \\
\hline Males & $76(86 \%)$ & $139(92 \%)$ & $108(92 \%)$ & $78(85 \%)$ \\
\hline Mean (SD) follow up (months) & $26(28)$ & $24(23)$ & $25(23)$ & $26(21)$ \\
\hline Range & $<1$ to 95 & $<1$ to 98 & $<1$ to 114 & $<1$ to 89 \\
\hline \multicolumn{5}{|l|}{ Underlying disease } \\
\hline $\mathrm{CAD}$ & $16(33 \%)$ & $114(75 \%)$ & $86(74 \%)$ & $63(68 \%)$ \\
\hline DCM & $9(17 \%)$ & $25(17 \%)$ & $21(18 \%)$ & $21(23 \%)$ \\
\hline DYS & $10(20 \%)$ & $5(3 \%)$ & $3(3 \%)$ & $4(4 \%)$ \\
\hline Other & $15(30 \%)$ & $7(5 \%)$ & $7(6 \%)$ & $4(4 \%)$ \\
\hline \multicolumn{5}{|l|}{ Ejection fraction } \\
\hline Mean (SD) EF & $47(17 \%)$ & $37(11 \%)$ & $29(12 \%)$ & $30(12 \%)$ \\
\hline $\mathrm{EF}<30 \%$ & $16(30 \%)$ & $100(66 \%)$ & $95(81 \%)$ & $75(81 \%)$ \\
\hline$\overline{E F} \geqslant 30 \%$ & $35(70 \%)$ & $51(34 \%)$ & $22(19 \%)$ & $17(19 \%)$ \\
\hline \multicolumn{5}{|l|}{ Arrhythmia history } \\
\hline No arrhythmia & $5(10 \%)$ & $8(5 \%)$ & $2(2 \%)$ & $2(2 \%)$ \\
\hline VT & $14(30 \%)$ & $53(35 \%)$ & $39(33 \%)$ & $25(27 \%)$ \\
\hline VF & $22(43 \%)$ & $44(29 \%)$ & $35(30 \%)$ & $28(30 \%)$ \\
\hline $\mathrm{VT}+\mathrm{VF}$ & $9(15 \%) 4$ & $6(30 \%) 4$ & $1(35 \%)$ & $37(40 \%)$ \\
\hline
\end{tabular}

*ICD implantation according to the CAT or MADIT study protocols. ${ }^{1011}$

CAD, coronary artery disease; DCM, dilated cardiomyopathy; DYS, dysplasia ; EF, ejection fraction; VT, ventricular tachycardia; VF, ventricular fibrillation.

(NYHA) functional class of heart failure by two experienced cardiologists. In addition to the traditional functional NYHA classification of heart failure (NYHA I-IV), we added two hybrid categories because some of the patients could not be clearly classified into one NYHA class by the two interviewers. NYHA class I-II was assigned if patients had either no signs of heart failure or dyspnoea during severe exercise. NYHA class II-III was assigned in patients with dyspnoea during moderate or mild exercise. Fifty patients $(12 \%)$ were in NYHA class I-II, 151 (37\%) in class II, 117 $(29 \%)$ in class II-III, and the remaining 92 $(22 \%)$ in class III. No patient underwent ICD implantation in NYHA class IV. The clinical characteristics of the patients are listed in table 1.

\section{CARDIAC CATHETERISATION}

Before ICD implantation, all patients underwent cardiac catheterisation, coronary angiography, and left ventriculography. The left ventricular ejection fraction was calculated from the end diastolic and end systolic angiographic frames in a $30^{\circ}$ degree right anterior oblique projection. The extent of coronary lesions was assessed by visual interpretation. Coronary stenoses were considered significant when high grade stenoses $(>75 \%$ of the luminal diameter) were present. The results of the catheterisation studies are shown in table 1 .

PREOPERATIVE ELECTROPHYSIOLOGICAL STUDY All patients underwent a baseline electrophysiological study before implantation, after discontinuation of antiarrhythmic drug treatment for at least five drug half lives. Three quadripolar $7 \mathrm{~F}$ USCI electrode catheters (USCI Corporation, Billerca, Massachusetts, USA) were introduced through the femoral vein under general anaesthesia. The electrode catheters were placed in the high right atrium, the right ventricular apex, and across the tricuspid valve to record His bundle potentials. All patients were considered for an ICD on the basis of history and presence of spontaneous and inducible sustained ventricular tachycardia or ventricular fibrillation. ${ }^{12}$
DEVICE IMPLANTATION

After written informed consent, all patients were maintained under general anaesthesia throughout implantation of the ICD system. During the first five years (1984 to 1989), an epicardial defibrillation lead system was used, which was implanted through a median sternotomy or left anterior thoracotomy. ${ }^{13}$ Using this approach, the leads (two defibrillation patch electrodes, two myocardial screw-in pacing/sensing leads) were attached to the left and right ventricle. Since 1990, non-thoracotomy defibrillation lead systems were used at our institution. The transvenous defibrillation lead electrode system (Endotak lead, CPI, St Paul, Minneapolis, USA; TVL lead system, Ventritex, Sunnyvale, California, USA) is advanced through the subclavian or the cephalic vein into the right atrium and then to the right ventricle. The distal tip of the lead is lodged in the right ventricular apex. After evaluation of the defibrillation threshold the leads are tunnelled to the abdominal pocket subcutaneously and attached to the pulse generator, which is placed submuscularly. The implantation procedure has been reported in detail recently. ${ }^{13}$ At our institution pulse generators from different companies were implanted: Medtronic (St Paul, Minneapolis, USA), CPI, and Ventritex (Sunnyvale, California, USA), as described in detail elsewhere. ${ }^{12}{ }^{13}$ Since 1990, third generation ICDs with antibradycardia and antitachycardia pacing capabilities were implanted. ${ }^{14}$

\section{DEFIBRILLATION THRESHOLD TESTING}

Before defibrillation threshold testing, the $\mathbf{R}$ wave amplitude from the pacing/sensing leads was measured and a synchronised biphasic shock of 0.1 joule was delivered during sinus rhythm to determine the impedance of the defibrillation leads. The pulse width was adjusted according to the measured impedance. The defibrillation threshold testing was performed using a programmable stimulation/cardioverter defibrillator analyser (model HVS-02, Ventritex). Ventricular fibrillation was then induced by rapid ventricular pacing and initial defibrillation attempts were per- 
formed using a 20 joule shock delivered through the HVS-02. If ventricular fibrillation was successfully terminated with 20 joules, then additional testing with 15 joules, 10 joules, 8 joules, 5 joules, and 3 joules was performed until a minimum of two consecutive successful conversions occurred. This voltage was defined as the defibrillation threshold. If a 20 joule shock did not terminate ventricular fibrillation twice, a subcutaneous patch was implanted and defibrillation threshold testing was repeated. After the defibrillation threshold was determined, the leads were attached to the pulse generator, which was placed submuscularly, and the ability of the system to detect and terminate induced ventricular fibrillation was again tested with a 20 joule shock.

\section{PREDISCHARGE TESTING}

All patients underwent an electrophysiological study before discharge, at a mean (SD) of 7 (2) days (range 4 to 13 days) after ICD implant. Before testing, proper lead positioning was confirmed by chest $x$ ray. After ventricular fibrillation had been induced in all patients, proper sensing and termination of the arrhythmia by countershock was studied and the defibrillation threshold re-evaluated. In patients with inducible sustained monomorphic ventricular tachycardia, the efficacy and safety of three different antitachycardia pacing modes were studied, as described recently. ${ }^{14}$ The final programmed parameters for the device were chosen in accordance with the patient's clinical arrhythmia and the results of preoperative and predischarge electrophysiological test data. In patients with a clinical arrhythmia of ventricular fibrillation only, the device was programmed for defibrillation only, with the first shock voltage set at 10 joules over the defibrillation threshold. In patients with induced ventricular tachycardia, the patient was sent home with the most effective pacing mode tested during predischarge study. ${ }^{14}$

\section{FOLLOW UP}

All patients were followed in the outpatient clinic every two months. During these visits, the patient was questioned about the occur-

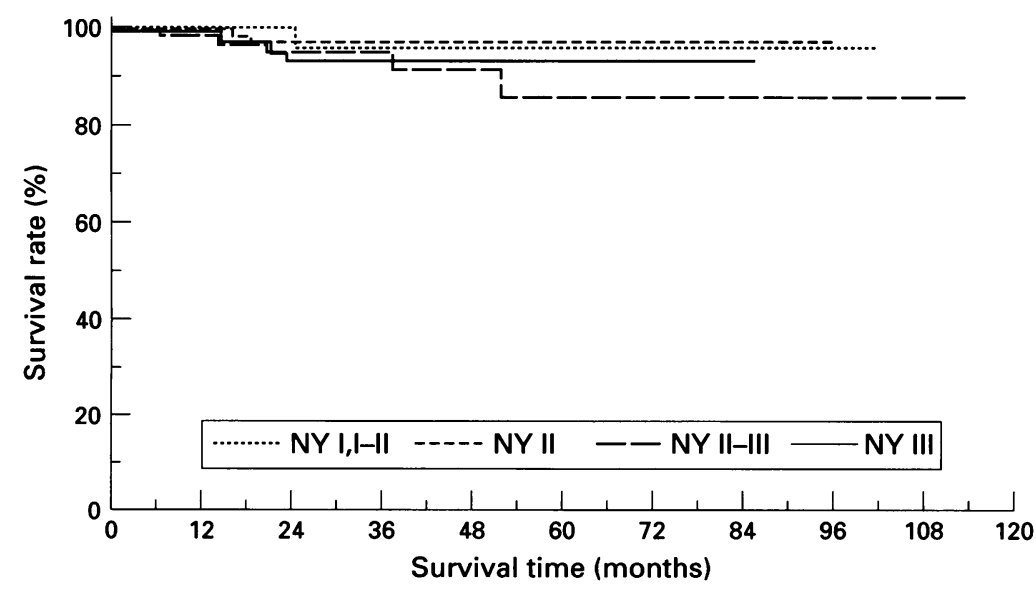

Figure 1 Kaplan-Meier survival curves in implantable cardioverter-defibrillator recipients (incidence of sudden death) in relation to the functional class of heart failure. NY, NYHA (New York Heart Association class). rence of any device discharges or symptoms such as palpitations, syncope, or dizziness. The device was interrogated and the pacing thresholds, $\mathbf{R}$ wave amplitudes, and lead impedance were measured. All reported episodes were verified by interviews with relatives or other treating physicians. Stored electrograms were retrieved and analysed with specifically designed equipment. Sudden death was defined as death occurring within one hour after the beginning of symptoms. A sudden arrhythmic death was diagnosed when postmortem analysis of stored electrograms showed that ventricular tachycardia or ventricular fibrillation was the underlying arrhythmia and had not been terminated by the device. In patients with witnessed unexpected deaths we were not able to interrogate the devices and therefore we classified these as sudden (nonarrhythmic) deaths. All deaths were verified and classified by interviews with relatives and physicians.

\section{STATISTICS}

Values are given as mean (SD). Statistical analysis was evaluated by unpaired Student's $t$ test, analyses of variance and Fisher's exact test. $P$ values $<0.05$ were considered significant. Life table analysis was performed according to the Kaplan-Meier method (LeaDesu statistic).

\section{Results}

\section{PERIOPERATIVE MORTALITY}

From January 1984 to May 1990, epicardial ICD implantation was performed in 209 patients (51\%) and the remaining 201 patients (49\%) underwent non-thoracotomy lead implantation from May 1990 (table 1). Perioperative deaths (within 30 days after ICD implantation) occurred in 12 patients (3\%): one was in NYHA class I-II, four were in class II, five were in class II-III, and the remaining two were in class III. Perioperative deaths occurred more often in patients with epicardial implantation (11/209 patients, $5 \%$ ) than in those with non-thoracotomy ICDs (1/201 patients, $<1 \%)(P<0.05)$. The cause of perioperative death was congestive heart failure in nine patients, while three patients died from ventricular arrhythmias: one patient from recurrent ventricular fibrillation not treatable by the ICD or additional antiarrhythmic drugs, and two from electromechanical dissociation.

\section{LONG TERM MORTALITY}

During a follow up of 28 (24) months (range $<1$ to 114 months), 90 patients $(23 \%)$ died: $14(4 \%)$ died suddenly (within one hour of the beginning of symptoms); nine of these $(2 \%)$ died from sudden arrhythmic death; five $(1 \%)$ also died suddenly but probably not from arrhythmic causes. Fifty five patients (14\%) died from cardiac causes (congestive heart failure, myocardial reinfarction) and 21 patients (5\%) from non-cardiac causes. We have been able to show that the incidence of sudden death was low in all groups (fig 1). There was 


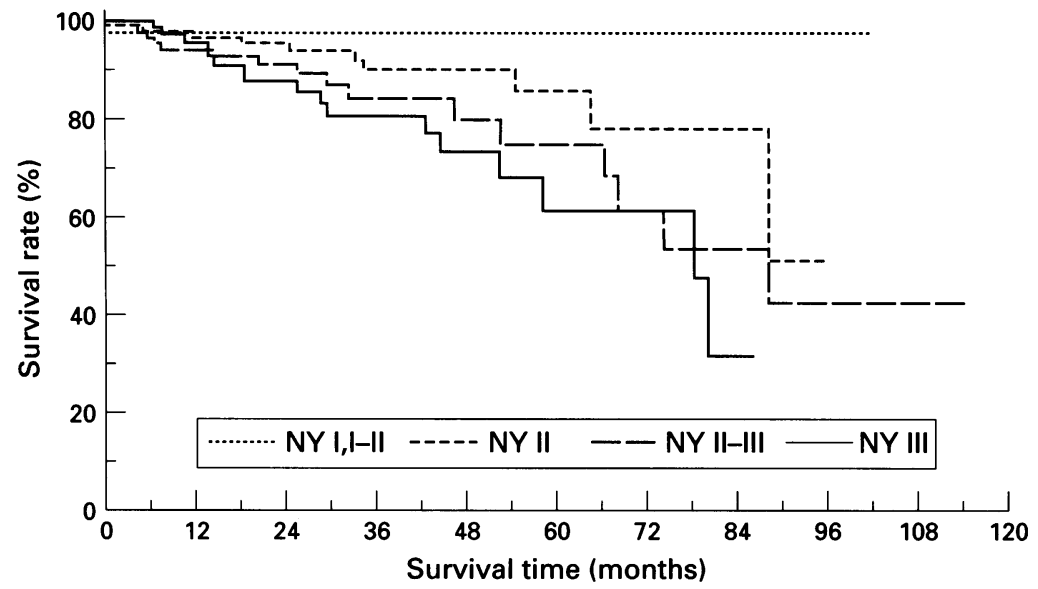

Figure 2 Kaplan-Meier survival curves in implantable cardioverter-defibrillator recipients (incidence of cardiac death) in relation to the functional class of heart failure. NY, NYHA (New York Heart Association class).

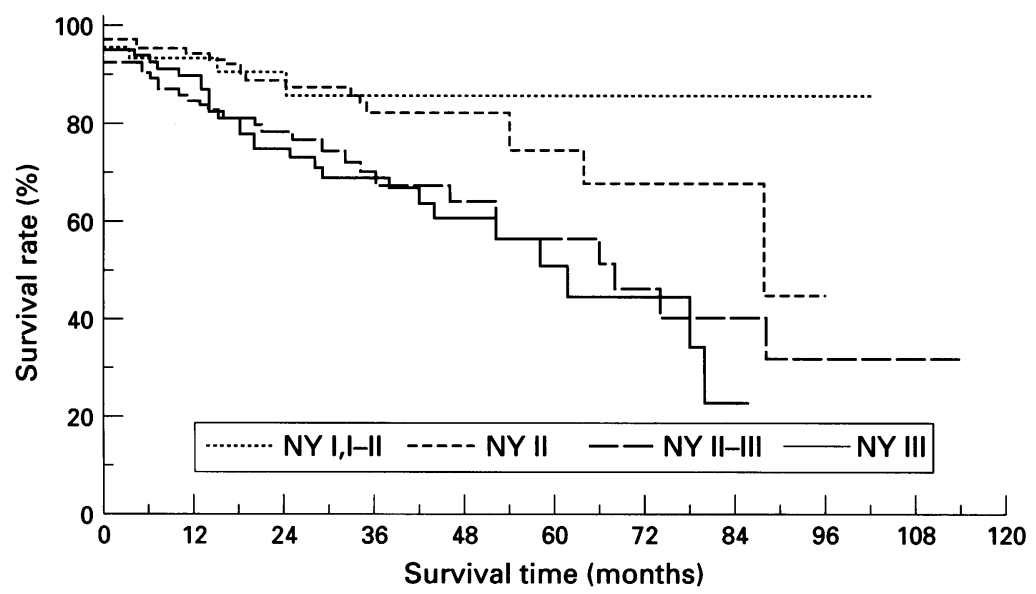

Figure 3 Kaplan-Meier survival curves in implantable cardioverter-defibrillator recipients (total mortality) in relation to the functional class of heart failure. NY, NYHA (New York Heart Association class).

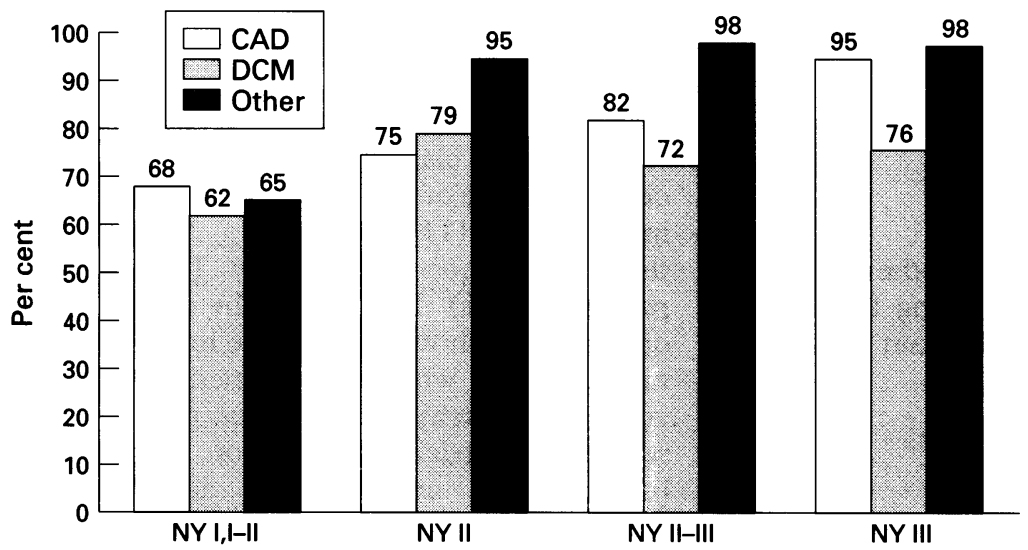

Figure 4 Incidence of ICD discharges in patients with coronary artery disease, dilated cardiomyopathy, or other aetiologies in relation to the functional class of heart failure. $I C D$, implantable cardioverter-defibrillator; $C A D$, coronary artery disease; $D C M$, dilated cardiomyopathy; NY, NYHA (New York Heart Association class).

an excellent survival rate, independent of the degree of left ventricular dysfunction. However, there was a higher cardiac death rate and a higher total mortality in patients in NYHA class II-III and class III than in patients in class I-II or class II (figs 2 and 3 ). Survival rates were clearly influenced by the functional class of heart failure.
INCIDENCE OF ICD SHOCKS

Over the follow up period, 338 patients (82\%) received ICD shocks, with a mean of 21 (43) shocks per patient (range 0 to 621 shocks per patient; median 17 shocks). Patients in NYHA class II (125/151 patients, $83 \%)$, class II-III (98/117 patients, $84 \%)$, and class III (83/92 patients, $90 \%$ ) received more frequent ICD discharges than patients in class I-II (32/50 patients, 64\%) $(\mathrm{P}<0.05)$. However, we could not show a significant difference in the incidence of ICD discharges between patients with coronary disease, dilated cardiomyopathy, or other disease (fig 4). Similar results were observed in the mean number of ICD shocks per patient: there was a higher mean number of shocks in patients in NYHA class II (18 (32) shocks, range 0 to 233; median 11), class II-III (19 (25) shocks, range 0 to 139; median 15), and class III (27 (36) shocks, range 0 to 228; median 21) than in patients in class I-II (12 (19) shocks, range 0 to 80 ; median 8) $(P<0.05)$. No significant differences were found between patients with coronary disease, dilated cardiomyopathy, or other aetiologies (fig 5).

\section{OCCURRENCE OF ICD SHOCKS}

As stated, 338 patients $(82 \%)$ received ICD shocks during a period of more than 10 years. We studied the occurrence of ICD shocks in relation to the degree of heart failure. The interval between ICD implantation and the first ICD shock was significantly shorter in patients in NYHA class II, II-III, and III compared to class I-II $(P<0.05)$ (table 2). In patients in NYHA class II, II-III, and III, $42-48 \%$ of ICD discharges were observed within the first six months after implantation, compared to $34 \%$ in patients in class I-II (NS). Within the first year after ICD implantation, $57-64 \%$ of patients had had ICD discharges in NYHA class II, II-III, and III, compared to $46 \%$ of patients in class I-II (NS) (fig 6). In all patients we tried to differentiate appropriate from inappropriate shocks. With the present ICDs, stored electrograms are available to confirm inappropriate or appropriate shocks; however, this was not possible in first and second generation devices. Keeping this in mind, 338 patients received appropriate shocks, while inappropriate shocks due to atrial fibrillation or sinus tachycardia were observed in 28 patients ( $7 \%$ ).

\section{SURVIVAL AFTER THE FIRST SHOCK}

To study the survival of patients after ICD implantation and therefore the benefit derived from the treatment, we evaluated follow up data after the first shock. We found that the interval between the first shock and the end of the mean follow up (June 1995) was 25 (22) months (range $<1$ to 112 months). After the first shock, mean survival time was 27 (24) months (range $<1$ to 106 months) in patients in NYHA class I-II, 25 (19) months (range $<1$ to 91 months) in class II, 25 (25) months (range $<1$ to 112 months) in class II-III, and 25 (21) months (range $<1$ to 83 months) in 


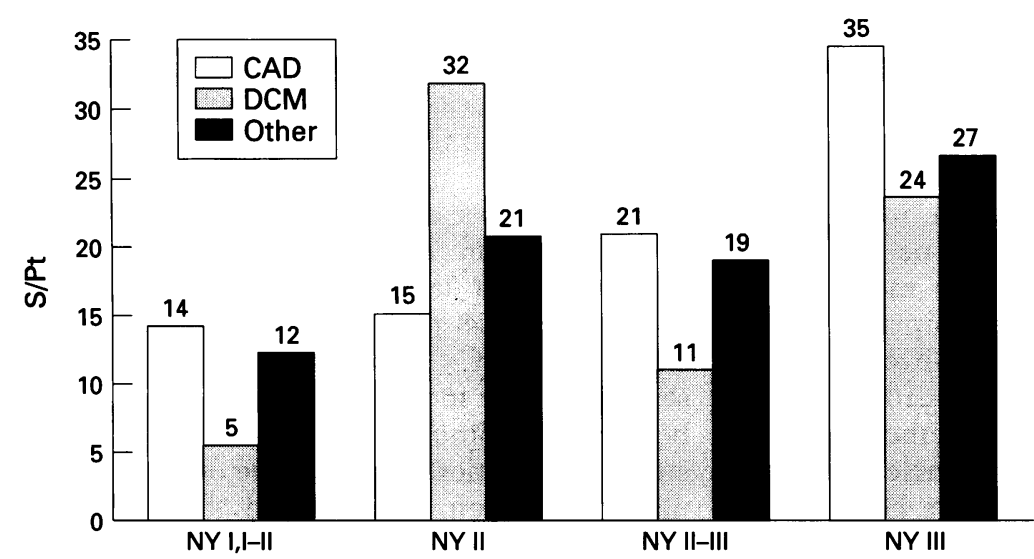

Figure 5 Mean number of ICD discharges per patient in patients with coronary artery disease, dilated cardiomyopathy, or other aetiologies in relation to the functional class of heart failure. ICD, implantable cardioverter-defibrillator; $C A D$, coronary artery disease; DCM, dilated cardiomyopathy; NY, NYHA (New York Heart Association class); Pt, patient; $S$, shock.

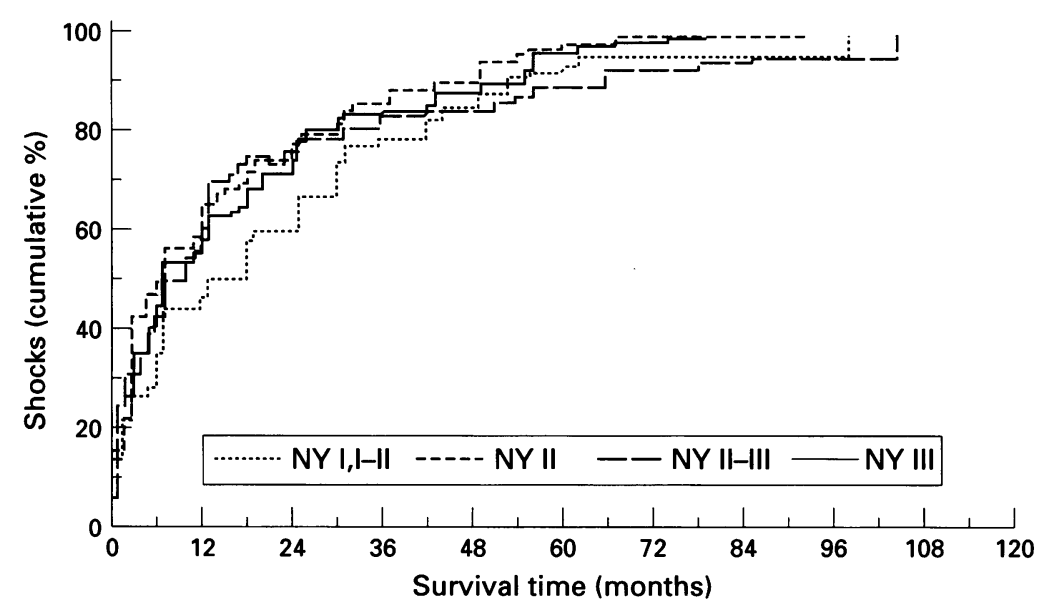

Figure 6 Occurrence of shocks (cumulative) after installation of implantable cardioverter-defibrillator (ICD) in relation to the functional class of heart failure. NY, NYHA (New York Heart Association class).

class III. There were no significant differences in mean survival times after the first shock and the end of the follow up between patients with mild (NYHA class I-II), moderate (NYHA class II-III), or severe left ventricular dysfunction (NYHA class III).

\section{ANTITACHYCARDIA PACING}

From 1990 we implanted third generation ICDs with antitachycardia pacing capabilities. ${ }^{14}$ Because many patients had received first and second generation devices, antitachycardia pacing activity was excluded from the present analysis. However, the role of antitachycardia pacing in patients with third generation cardioverter defibrillators has been described in detail by our group elsewhere. ${ }^{14}$
ADDITIONAL TREATMENT

After cardioverter defibrillator implantation, 153 patients $(37 \%)$ received digitalis, 230 $(56 \%)$ were treated with diuretics, and 11 (3\%) with $\beta$ blocking agents during follow up. Class I antiarrhythmic drugs (propafenone, mexiletine, flecainide) were given to 28 patients $(7 \%)$, amiodarone was used in 47 (11\%), and $173(42 \%)$ were treated with sotalol; 217 (53\%) received angiotensin converting enzyme (ACE) inhibitors (table 2). There were significant differences in the incidence of digitalis and diuretic treatment between patients with mild, moderate, or severe heart failure $(P<0 \cdot 05)$. Patients in NYHA class III received ACE inhibitors more often than patients in NYHA class I-II, II, or II-III; however, these differences were not statistically significant. In addition, no significant differences were observed in the antiarrhythmic drug treatment (class I, amiodarone, sotalol) between the different patient groups.

\section{Discussion}

There is little doubt of the efficacy of cardioverter-defibrillator treatment in the termination of life threatening ventricular tachyarrhythmias; however, the benefits of ICD treatment in patients with ventricular tachycardia or ventricular fibrillation and impaired left ventricular function are still unclear. ${ }^{1516}$ There are only two published reports comparing the outcome after ICD treatment in relation to the functional class of heart failure or the degree of left ventricular dysfunction during a relatively short follow up. ${ }^{17}{ }^{18}$ In the present study we report on the outcome after ICD implantation with respect to the functional class of heart failure and left ventricular ejection fraction during a long term follow up of more than 10 years. In general, there are two important aspects of ICD treatment in patients with impaired left ventricular function: (1) to evaluate the potential benefit of ICD treatment on survival; (2) to see whether the ICD will serve as a "bridge" to heart transplantation in patients with end stage ventricles who are awaiting a donor heart. ${ }^{19}$

RISK OF SUDDEN DEATH IN HEART FAILURE Previously published data on survival of patients with ventricular tachyarrhythmias treated with antiarrhythmic drugs or antitachycardia surgery suggest that left ventricular function is an independent predictor of

Table 2 Drug treatment after ICD implantation

\begin{tabular}{|c|c|c|c|c|}
\hline & \multicolumn{4}{|c|}{ NYHA class } \\
\hline & $I-I I$ & $I I$ & $I I-I I I$ & III \\
\hline $\begin{array}{l}\text { No of patients } \\
\text { Digitalis } \\
\text { Diuretics } \\
\beta \text { Blockers } \\
\text { Antiarrhythmic drugs }\end{array}$ & $\begin{array}{l}50 \\
8(16 \%) \\
17(34 \%) \\
1(2 \%)\end{array}$ & $\begin{array}{c}151 \\
45(30 \%) \\
75(50 \%) \\
7(5 \%)\end{array}$ & $\begin{array}{c}117 \\
48(41 \%) \\
72(62 \%) \\
1(1 \%)\end{array}$ & $\begin{array}{l}92 \\
52(57 \%) \\
66(72 \%) \\
2(2 \%)\end{array}$ \\
\hline $\begin{array}{l}\text { Class I } \\
\text { Amiodarone } \\
\text { Sotalol } \\
\text { ACE inhibitors }\end{array}$ & $\begin{array}{c}2(4 \%) \\
4(8 \%) \\
19(38 \%) \\
18(36 \%)\end{array}$ & $\begin{array}{l}10(7 \%) \\
14(9 \%) \\
62(41 \%) \\
81(54 \%)\end{array}$ & $\begin{array}{c}5(4 \%) \\
17(15 \%) \\
50(43 \%) \\
60(51 \%)\end{array}$ & $\begin{array}{l}11(12 \%) \\
12(13 \%) \\
42(46 \%) \\
58(63 \%)\end{array}$ \\
\hline
\end{tabular}

$\mathrm{ACE}$, angiotensin converting enzyme. 
recurrent events and survival. ${ }^{20-22}$ In patients with life threatening ventricular tachyarrhythmias and severely impaired left ventricular dysfunction three year arrhythmia recurrence rate has been reported to be approximately $50 \%{ }^{4}$ In the V-Heft II trial the incidence of sudden death was reported to be as high as $30 \%$ during a follow up of 66 months. ${ }^{23}$ In comparison, patients with implanted cardioverter defibrillators have an excellent outcome, with very low sudden death rates. ${ }^{24} 25$ However, it is still unclear whether the ICD will prolong life and it is also unclear whether patients with moderate or severe heart failure will benefit from ICD treatment or not. ${ }^{26}$ Any discussion of such an approach needs to address not only the benefit of ICD treatment on sudden death rate and survival but also, of course, the risks and complication rates of ICD treatment, particularly in patients with poor left ventricular function.

\section{SURVIVAL AFTER ICD IMPLANTATION}

The fact that sudden death is one of the major problems in patients with left ventricular dysfunction has been discussed in detail. ${ }^{18} 1922$ Cardioverter defibrillator treatment can prevent sudden death both in patients with normal or abnormal left ventricular function..$^{18}$ In the present study we showed a three year, five year, and seven year survival of $92-96 \%$ for arrhythmic mortality in NYHA class I, II, and III, while in patients in class II-III the three year survival was $94 \%$, and the five and seven year survival was $84 \%$. These results are in accordance with a five year survival of $96-99 \%$ for arrhythmic mortality in patients with a left ventricular ejection fraction $<30 \% .{ }^{24} 27$ In contrast to the excellent results in the prevention of sudden death, prognosis of ICD patients is clearly influenced by the underlying disease and the degree of left ventricular dysfunction. ${ }^{72}$ Initial reports showed a survival rate (cardiac death) of $67-87 \%$ at two years of follow up. ${ }^{7}$ Recent reports with a longer follow up suggest a worse prognosis in patients with an ICD and impaired left ventricular function: Axtell $e t a l^{27}$ reported a five year survival rate of $60 \%$ for cardiac mortality, while Mehta et $a l^{18}$ observed a four year survival rate of $85 \%$ from cardiac mortality in patients with moderate left ventricular dysfunction and $59 \%$ in patients with severe left ventricular impairment. These data are in accordance with the present study, and our four year survival from cardiac death was $81-89 \%$ in patients with moderate left ventricular dysfunction (NYHA class II, II-III) and $70 \%$ in patients with severe dysfunction (NYHA class III). Therefore, in addition to ICD implantation, appropriate and aggressive treatment of heart failure is necessary..$^{290}$

INCIDENCE AND OCCURRENCE OF SHOCKS

The incidence of appropriate ICD shocks over a two to five year follow up period has been reported to be in the range of $33 \%$ to $70 \% .^{3132}$ In addition, the incidence of discharges was $45 \%$ in patients with an ejection fraction of $<30 \%$, compared to $32 \%$ with an ejection fraction of $>40 \% .{ }^{31}$ These observations were not confirmed in the study by Mehta et $a l^{18}$ where ICD shocks occurred in $66 \%$ of patients with an ejection fraction of $>30 \%$ and in $62 \%$ of patients with an ejection fraction of $<30 \%$ (NS). Schlepper et $a l^{24}$ found that 27 patients (31\%) with an ejection fraction of $>30 \%$ experienced at least one appropriate shock, compared to 48 patients $(51 \%)$ with an ejection fraction of $<30 \%(P<0.05)$. In the present study, the incidence and time occurrence between ICD implantation and first shock was studied in relation to the degree of left ventricular dysfunction. We showed that the incidence and mean number of shocks were higher in patients with moderate or severe left ventricular dysfunction, particularly in patients in NYHA class III compared to patients in NYHA class I-II. However, as we did not analyse the shock occurrences in relation to left ventricular ejection, a comparison between other studies and our results is difficult or impossible. An interesting observation is the time occurrence of the first shock after ICD implant: we could show that the period from device implantation to the first shock was shorter in patients with severe left ventricular dysfunction (mean 16 to 19 months) than in patients with lesser degrees of heart failure (22 months). Similar observations have been made by Myerburg et $\mathrm{al}^{31}$ and Vester et $a .^{33}$

\section{CLINICAL IMPLICATIONS}

Since the incidence of sudden death in patients with poor left ventricular function is high, even in patients on converting enzyme inhibitors, the automatic cardioverter defibrillator is a useful tool in their management. We have shown in this study, as have others, that patients with moderate as well as severe left ventricular dysfunction benefit from ICD treatment and survive for long time after the first shock. On the other hand, one has to keep in mind that survival after ICD implant is clearly influenced by the degree of left ventricular function. Additional aggressive treatment of heart failure is necessary to prevent cardiac death, and heart transplantation should be discussed as early as possible in selected patients. The hypothesis that ICD treatment can serve as a "bridge" to heart transplantation and could avoid sudden death on the waiting list has to be proven by a prospective study. However, the role of ICD treatment as bridge to heart transplantation was not an issue in this study and was recently discussed elsewhere. ${ }^{19}$

\section{LIMITATIONS OF THE STUDY}

The data from our study were not obtained in a randomised fashion. It would, of course, be better to compare survival data in patients with different degrees of heart failure in one group with an ICD and in another group without such a device. However, for ethical reasons this is not possible. In addition, patients were treated during the follow up period with a range of drugs, and at the beginning of ICD treatment, ACE inhibitors were not available. Therefore, drug treatment after ICD implan- 
tation during follow up (over more than 10 years) was not performed in all patients with the same regimen. The role of antitachycardia pacing is difficult to analyse in the present patient population because at the start of our study period third generation ICDs were not available; we therefore excluded antitachycardia pacing treatments from the present analysis. It is possible to differentiate appropriate from inappropriate shocks with the present generation of ICDs but this was not possible in first and second generation devices.

1 Cappucci A, Boriani G. Drugs, surgery, cardioverter defibrillator: a decision based on the clinical problem. $P A C E$ 1993;16:519-26.

2 Gillum RF. Sudden coronary death in the United States. Circulation 1989;79:756-65.

3 Franciosa JA, Wilen M, Ziesche $S$, Cohn JN. Survival in Franciosa JA, Wilen $M$, Ziesche S, Cohn JN. Survival in
mean with severe chronic left ventricular failure to either mean with severe chronic left ventricular failure to either
coronary heart disease or idiopathic dilated cardiomyopathy. Am $\mathcal{F}$ Cardiol 1983;51:831-6.

4 Swerdlow CD, Winkle RA, Mason JW. Determinants of survival in patients with ventricular tachyarrhythmias. $N$ Engl f Med 1983;308:1436-42.

5 Bigger JT, Fliess JL, Kleiger R, Miller JP, Rocnitzky LM, the Multicenter Post-Infarction Research Group. The relationship among ventricular arrhythmias, left ventricuar dysfunction and the mortality in the 2 years after myocardial infarction. Circulation 1984;69:250-8.

6 Massie BM, Conway M. Survival of patients with congestive heart failure: past, present, and future prospects. Circulation 1987;75:11-19.

7 Fogoros RN, Elson JJ, Bonnet CA, Fiedler SB, Burkholder JA. Efficacy of the automatic implantable cardioverterdefibrillator in prolonging survival in patients with severe underlying heart disease. $f \mathrm{Am}$ Coll Cardiol 1990;16: 381-6.

8 Tchou PJ, Kadri N, Anderson J, Caceres JA, Jazayeri M, Akhtar M. Automatic implantable cardioverter defibrillators and survival in patients with ventricular dysfunction tors and survival in patients with ventricular dysfunction and malignant venti.

9 Axtell K, Tchou PJ, Akhtar M. Survival in patients with depressed left ventricular function treated with implantable defibrillator. $P A C E$ 1991;14:291-6.

10 Moss AJ. Prospective antiarrhythmic studies assessing prophylactic pharmacological and device therapy in high risk coronary patients. PACE 1992;15:694-6.

11 The Cardiomyopathy Trial Investigators. Cardiomyopathy trial. PACE 1993;16:576-81.

12 Trappe HJ, Pfitzner P, Fieguth HG, Wenzlaff $P$, Kielblock $B$, Klein $H$. Nonpharmacological therapy of ventricular tachyarrhythmias: observations in 554 patients. PACE 1994;17:2172-7.

13 Trappe HJ, Klein $\mathrm{H}$. Clinical results with implantable cardioverter-defibrillator therapy. In: Singer I, ed. Publishing Company, 1994:487-505.

14 Trappe HJ, Klein H, Kielblock B. Role of antitachycardia pacing in patients with third generation cardioverter pacing in patients with third gene
defibrillators. $P A C E 1994 ; 17: 506-13$.

15 The Cardiac Arrhythmia Suppression Trial Investigators. Preliminary report: effect of encainide and flecainide on mortality in randomized trial of arrhythmia suppression and myocardial infarction. $N$ Engl $f$ Med 1989;321: 406-12.

16 Furman S. AICD benefit. PACE 1989;12:399-400.

17 Akhtar M, Jazayeri M, Sra J, Sra J, Tchou P, Rouang K, et al. Implantable cardioverter defibrillator for prevention of sudden cardiac death in patients with ventricular tachysudden cardiac death in patients with ventricular tachy-
cardia and ventricular fibrillation. PACE 1993;16: cardia $11-18$.

18 Mehta D, Saksena S, Krol RB, John T, Saxena A, Raju R, et al. Device use patterns and clinical outcome of implantable cardioverter defibrillator patients with moderate and severe impairment of left ventricular function. $P A C E$ 1993;16:179-85.

19 Trappe HJ, Wenzlaff P. Cardioverter defibrillator therapy as a bridge to heart transplantation. $P A C E$ 1995;18 622-31.

20 Wilber DJ, Garan H, Finkelstein D. Out-of-hospital cardiac arrest: use of electrophysiologic testing in the prediction of long-term outcome. $N$ Engl 7 Med 1988;318 19-24.

21 Lawrie GM, Pacifico A, Kaushik R, Nahas C, Earle N. Factors predictive of results of direct ablative operations for drug-refractory ventricular tachycardia: analysis of 80 patients. $\mathcal{F}$ Thorac Cardiovasc Surg 1991;73:1239-47.

22 Stevenson WG, Stevenson LW, Middlekauf HR, Saxon LA. Sudden death prevention in patients with advanced ve. Sudden death prevention in patients with advanced

23 Cohn J, Johnson G, Ziesche S, Cobb F, Francis G, Tristan $\mathrm{F}$, et al. A comparison of enalapril with hydralazine$\mathrm{F}$, et al. A comparison of enalapril with hydralazineisosorbide dinitrate in treatment of chronic congestive

24 Schlepper M, Neuzner J, Pitschner HF. Implantable cardioverter defibrillator: effect on survival. $P A C E$ 1995;18 $569-78$.

25 Nisam S, Kaye A, Mower MM, Hull M. AICD automatic cardioverter defibrillator clinical update: 14 years experience in over 34,000 patients. PACE 1995;18:142-7.

26 Böcker D, Block M, Isbruch F, Wietholt D, Hammel D, Borggrefe $\mathrm{M}$, et al. Do patients with implantable defibrillators live longer? $f \mathrm{Am}$ Coll Cardiol 1993;21:1638-44.

27 Axtell K, Tchou PJ, Akhtar M. Survival in patients with depressed left ventricular function treated with implantable defibrillator. PACE 1991;14:291-6.

28 Trappe HJ, Fieguth HG, Klein H, Wenzlaff P, WeberConrad O, Schöhl W, et al. Role of the underlying etiology in patients with an implantable cardioverter defibrillator. Med Klin 1993;88:362-70.

29 Swerdberg K, Idanpaan-Heikkila U, Remes J, the Consensus Trial Study Group. Effects of enalapril on mortality in severe congestive heart failure. Results of the mortality in severe congestive heart failure. Results of the Study (CONSENSUS). $N$ Engl $f$ Med 1987; 316: Study (CON-35.

30 Ball SG, Hall AS, Mackintosh AT, the AIRE Study Group Effect of ramipril and morbidity of survivors of acute myocardial infarction with clinical evidence of heart failure. Lancet 1993;342:821-8.

31 Myerburg RJ, Luceri RM, Thurer R, Cooper DK, Zaman $\mathrm{L}$, Interian A, et al. Time to first shock and clinical outcome in patients receiving an automatic implantable cardioverter-defibrillator. $尹 \mathrm{Am}$ Coll Cardiol 1989;14 508-14.

32 Kim SG, Fisher JD, Choue CW, Gross J, Roth J, Ferrick $\mathrm{KF}$, et al. Influence of left ventricular function on outcome of patients treated with implantable defibrillators. Circulation 1992;85:1304-10.

33 Vester EG, Kuhls S, Altenvoerde G, Perings C, Winter J, Heydthauser $M$, et al. Ten-years follow-up after automatic cardioverter/defibrillator-implantation: determining factors of survival and shock incidence [abstract]. Eur f Cardiol 1994;15:187. 